\title{
Is it correct for a woman with multiple sclerosis to forgo medication because she may become pregnant?
}

\author{
É correto deixar uma mulher com esclerose múltipla sem medicamento \\ porque pode ser que ela engravide?
}

Multiple sclerosis (MS) is an immune-mediated neurodegenerative disease that may progress with physical and cognitive disability that lead to a substantial reduction in the quality of life for patients and their families. Multiple sclerosis is a disease of young adults, and its predominance among females is well established. The primary population typically affected by MS comprises young women who nowadays receive assurances that pregnancy will not have a deleterious effect on the disease ${ }^{1}$. However, the withdrawal of all MS medications is recommended to women who choose to become pregnant or experience an unplanned pregnancy ${ }^{2}$. In fact, it is recommended that a woman who does not make use of effective methods of contraception should not be treated for MS. The delay or interruption of MS treatment may allow the disease to progress in a shorter period of time ${ }^{3}$. Therefore, is it correct to allow a woman with MS to forgo medication because she may get pregnant? Are the drugs used for treating MS associated with worse outcomes for the mother or her child?

According to the Food and Drug Administration criteria for drug safety during pregnancy ${ }^{4}$, interferon beta, fingolimod and natalizumab are class $\mathrm{C}$ drugs, while glatiramer acetate is a class $\mathrm{B}$ drug. For both drug classes, this means that the benefits may outweigh the risks of the treatment, especially for glatiramer acetate.

Systematic reviews of the literature in regard to maternal exposure to interferon beta and glatiramer acetate have not shown any association of maternal or neonatal complications that may be attributable to the drugs ${ }^{2,5}$. The lack of published cases reporting specific complications may reflect the fact that these complications are uncommon, if at all present.

The guidelines for treating women with MS who may become pregnant need to be revised. At the moment, the recommendation is to treat only those who are using a safe and efficient contraceptive method and do not intend to become pregnant. While some authors seem to be more flexible in regard to drug treatment ${ }^{6,7}$, other authors insist that there is a lack of evidence regarding drug safety and maintain this rigid rule for women with $\mathrm{MS}^{8}$.

Would it be acceptable that a woman might be treated with glatiramer acetate or interferon beta and still become pregnant? Although safety data on exposure for newer drugs like natalizumab and fingolimod are still lacking ${ }^{9}$, there seems to be strong data on the safety of glatiramer acetate $e^{10,11}$ and interferon beta ${ }^{11,12}$ exposure during pregnancy. Is it time to rethink our recommendations? After all, why should a woman with MS remain untreated because she may become pregnant? This attitude is not based on scientific evidence and puts the patient at risk at a time when MS can be treated successfully.

Yara Dadalti Fragoso

\section{References}

\footnotetext{
1. D'hooghe MB, Nagels G, Uitdehaag BM. Long-term effects of childbirth in MS. J Neurol Neurosurg Psychiatry 2010:81:38-41.

2. Lu E, Wang BW, Guimond C, Synnes A, Sadovnick D, Tremlett H. Disease-modifying drugs for multiple sclerosis in pregnancy: a systematic review. Neurology 2012;79:1130-1135.

3. Bergamaschi R, Quaglini S, Tavazzi E, et al. Immunomodulatory
}

therapies delay disease progression in multiple sclerosis. Mult Scler 31 May 2012 [Epub ahead of print].

4. FDA pregnancy categories. Available at: http://safefetus.com/search. php/index/fda and at http://www.drugs.com/pregnancy-categories. html. Both accessed on 8 May 2013.

5. Finkelsztejn A, Brooks JB, Paschoal FM Jr, Fragoso YD. What can

Correspondence: Yara Dadalti Fragoso; Department of Neurology, Universidade Metropolitana de Santos; Santos SP - Brazil; E-mail:yara@bsnet.com.br Conflict of interest: There is no conflict of interest to declare.

Received 08 May 2013; Received in final form 29 May 2013; Accepted 05 June 2013. 
we really tell women with multiple sclerosis regarding pregnancy? A systematic review and meta-analysis of the literature. BJOG 2011;118:790-797.

6. Houtchens MK, Kolb CM. Multiple sclerosis and pregnancy: therapeutic considerations. J Neurol 2013;260:1202-1214.

7. Ghezzi A, Annovazzi P, Portaccio E, Cesari E, Amato MP. Current recommendations for multiple sclerosis treatment in pregnancy and puerperium. Expert Rev Clin Immunol 2013;9:683-692.

8. Charles JA, Tremlett H, Lu E, Guimond C, Sadovnick AD. Diseasemodifying drugs for multiple sclerosis in pregnancy: a systematic review. Neurology 2013;80:1068-1069.
9. Houtchens MK, Kolb CM. Multiple sclerosis and pregnancy: therapeutic considerations. J Neurol 2013;260:1202-1214.

10. Giannini M, Portaccio E, Ghezzi A, et al. Pregnancy and fetal outcomes after Glatiramer Acetate exposure in patients with multiple sclerosis: a prospective observational multicentric study. BMC Neurol 2012;12:124.

11. Fragoso YD, Boggild M, Macias-Islas MA, et al. The effects of longterm exposure to disease-modifying drugs during pregnancy in multiple sclerosis. Clin Neurol Neurosurg 2013;115:154-159.

12. Amato MP, Portaccio E, Ghezzi A, et al. Pregnancy and fetal outcomes after interferon- $\beta$ exposure in multiple sclerosis. Neurology 2010;75:1794-1802 